\title{
Feasibility of learning dermatology among undergraduates through online means: the impact of COVID-19
}

\section{Sagar Pokhrel', Neelam Dahal', Dhan Kesar Khadka², Samir Shrestha ${ }^{3}$}

\author{
${ }^{1}$ B.P. Koirala Institute of health Sciences, Dharan, Nepal, ${ }^{2}$ Department of Dermatology and Venereology, B.P. Koirala \\ Institute of Health Sciences, Dharan, Nepal, ${ }^{3}$ Department of Dermatology and Venereology, B.P. Koirala Institute of Health \\ Sciences, Dharan, Nepal
}

Corresponding author: Samir Shrestha, MD, E-Mail: shresthasambec731@gmail.com

\begin{abstract}
Background: The outbreak of the deadly disease COVID-19 has shaken the entire world. The pandemic has resulted in a global lockdown affecting all areas of life, including medical education. This has impeded the traditional way of teaching and learning activities and forced educational institutions such as medical universities to shift rapidly to distance and online learning. Aims and Objectives: The aim was to find out the impact of COVID-19 and the perception of undergraduate students of B.P. Koirala Institute of Health Sciences (BPKIHS) of learning dermatology through online means. Methods: A cross-sectional study was conducted with a self-administered online questionnaire. The inclusion criteria were all MBBS third and fourth years students of BPKIHS willing to participate in the study. Result: A total of 151 participants agreed to complete the online survey questionnaire. The overall attitude toward online education was positive. The majority of students agreed that online learning material should be of high quality for online education $(66.2 \%)$ and that online learning will bring new opportunities for organizing teaching and learning (62.3\%). Zoom and Dudal were the most common online tools used by students. The geographic location, lack of past experience in using online tools, and communication barriers such as a poor Internet connection and frequent electricity cutoffs were identified by students as the main barriers to online education. Conclusion: Although the COVID-19 pandemic culminated in the lockdown of medical universities, it provided opportunities for bringing innovations into effect. Such large-scale studies are missing in developing countries such as Nepal, thus further research is needed to explore these possibilities nationwide.
\end{abstract}

Key words: COVID-19; feasibility; online learning

\section{INTRODUCTION}

The COVID-19 pandemic, which began in December 2019 in Wuhan, China, has affected all areas of life, including education. As the situation worsened, the global lockdown culminated in a lockdown of educational institutions, which affected over 1.5 billion students as per a report by UNESCO $[1,2]$. The pandemic has challenged the well-established traditional structure of undergraduate medical education, whose backbone has been in-person teaching, as social distancing measures impeded students from assembling in learning labs, lecture halls, and small-group rooms $[3,4]$. The pandemic has forced educational institutions to shift rapidly to distance and online learning, and hence novel methods of delivering education to medical students have been introduced [5]. Lectures have rapidly been developed to be delivered online as webinars using various platforms, such as Zoom [6]. Using a similar web portal for online teaching by medical undergraduates would be an innovative step in Nepalese medical education. However, digital medical education is in its infancy in the geographically challenging and mountainous country of Nepal [7].




Online learning systems, which may be synchronous or asynchronous, are web-based software for distributing, tracking, and managing courses over the Internet. It involves the implementation of advancement in technology to direct, design, and deliver learning content and to facilitate two-way communication between students and faculties [8].

Undergraduate dermatology exposure is variable, limited, and often suboptimal due to a restricted time schedule, which has been further compromised by the pandemic $[9,10]$. Previous studies have shown postgraduate students' perspective on these online classes, yet undergraduate students' perception is missing and it is even more important as this group is entirely dependent on online teaching during the pandemic [11]. It remains unclear whether students are ready and willing to make use of online education to obtain quality learning opportunities, which could change students' attitudes and impressions completely, and consequently the general theme of online education [12].

In developed countries, resources for online learning that have made online education feasible are easily available. However, there are limitations in developing countries such as Nepal that hinder online teaching and learning. So far, there has been a paucity of research regarding this aspect. Hence, this study was designed to assess the individual's perspective regarding the tools and methods in terms of acceptability and the impact and the barriers being encountered, which would help to plan the future implementation of online education tools accordingly. Further, the study was designed to determine the impact of COVID-19 on undergraduate medical education, which would help policymakers in taking possible steps to lessen this impact nationwide.

The objectives of this study were to determine the impact of COVID-19 and the perception of undergraduate students of B.P. Koirala Institute of Health Sciences (BPKIHS) of learning dermatology through online means.

\section{MATERIALS AND METHODOLOGY}

This cross-sectional study was conducted after obtaining ethical clearance from the Undergraduate Medical Research Protocol Review Board (UM-RPRB) of BPKIHS (code: 06/2020, date of approval: Sep. 15, 2020). The study was conducted with a self-administered online questionnaire among third- and fourth-year MBBS students of BPKIHS from October 1 through November 30, 2020. After taking well-informed consent, data was collected from the 151 students. Non-probability consecutive sampling was used. The questionnaire was comprised of a sociodemographic profile of the subject, a contextual matter that comprised basic questions on the impact of COVID-19 and specific questions that regarded online education tools that the students have been using, perceptions and attitudes of the students toward online learning and barriers/challenges of online education faced by the students.

The variables were entered with Microsoft Excel and statistical analysis was performed with the IBM SPSS software, version 23. Continuous variables were expressed as means (+/- SD) or as medians, whereas categorical variables were expressed as numbers $(\%)$. A chi-square test was employed to analyze the data statistically. P values of $<0.05$ were considered statistically significant.

\section{RESULTS}

A total of 151 students agreed to participate in the study. The vast majority of the participants were male (68.2\%). Most of the participants were between 21- and 25 -year-old $(96.7 \%)$. Among these, $20.5 \%$ were from rural areas and $79.5 \%$ were from urban areas. The pandemic had affected the students in various aspects. Many were forced to leave colleges and return home, which had created undue stress regarding their study and career (Table 1).

The various devices used, the sources of Internet connection, the preferred online learning platforms, and the monthly expenditure of the students for the purpose of online learning systems are summarized in Table 2.

As for assessing the perceptions and attitude of the students toward online teaching, a majority agreed with easy access to the Internet $(91,60.3 \%)$, possessing satisfactory computer skills $(96,63.6 \%)$, the necessity of high-quality online learning materials (100, 66.2\%), online learning bringing new opportunities $(94,62.3 \%)$. Similarly, a majority disagreed with online education replacing the traditional approach $(98,64.9 \%)$, feeling comfortable to communicate $(50,33.1 \%)$, and medical universities adopting online learning more extensively $(66,43.7 \%)$ (Table 3). 
Table 1: Impact of COVID-19 on the students.

\begin{tabular}{lccc}
\hline Characteristics & \multicolumn{3}{c}{ Categories } \\
\cline { 2 - 4 } & $\begin{array}{c}\text { Agreed } \\
\mathbf{n ~ ( \% )}\end{array}$ & $\begin{array}{c}\text { Disagree } \\
\mathbf{n ~ ( \% )}\end{array}$ & $\begin{array}{c}\text { Neutra } \\
\mathbf{n ~ ( \% )}\end{array}$ \\
\hline Ability to carry out clinical & 6 & 137 & 8 \\
learning in wards & $(4)$ & $(90.7)$ & $(5.3)$ \\
Forced to return home & 98 & 24 & 29 \\
& $(64.9)$ & $(15.9)$ & $(19.2)$ \\
More concerned about the future & 117 & 5 & 29 \\
& $(77.5)$ & $(3.3)$ & $(19.2)$ \\
Worried of not being able to & 16 & 73 & 62 \\
afford college after the pandemic & $(10.6)$ & $(48.3)$ & $(41.1)$ \\
Mental stress and anxiety & 114 & 7 & 30 \\
increasing among medical & $(75.5)$ & $(4.6)$ & $(19.9)$ \\
students & & & \\
Medical education system & 143 & 1 & 7 \\
challenged worldwide, especially & $(94.7)$ & $(0.7)$ & $(4.6)$ \\
in resource-poor countries & & & \\
\hline
\end{tabular}

Table 2: Various parameters related to online teaching.

\begin{tabular}{llc}
\hline Characteristics & Category & $\begin{array}{c}\text { Frequency } \\
\mathbf{n}(\%)\end{array}$ \\
\hline Device used & Mobile & $42(27.8)$ \\
& Laptop & $24(15.9)$ \\
& Other & $5(3.3)$ \\
Source of the Internet & Combined & $80(53.0)$ \\
& Cellular data & $36(23.8)$ \\
& Wi-Fi & $82(54.3)$ \\
Frequency of Internet use & Combined & $33(21.9)$ \\
& Daily & $101(66.9)$ \\
& Several times a week & $39(25.8)$ \\
& Several times a month & $6(4)$ \\
Monthly expenditure (NRS) & Less often & $5(3.3)$ \\
& $<500$ & $21(13.9)$ \\
& 500-1000 & $65(43.0)$ \\
& 1000 - 1500 & $47(31.1)$ \\
Preferred tool & $>1500$ & $18(11.9)$ \\
& Dudal & $46(30.5)$ \\
& Zoom & $72(47.7)$ \\
& YouTube & $24(15.9)$ \\
& Google Classroom & $8(5.3)$ \\
& Facebook & $1(0.7)$ \\
\hline
\end{tabular}

A majority of the students noted poor Internet connection quality, frequent power cutoffs, difficulties in maintaining focus as the major challenges and barriers of online teaching. However, they did not consider the lack of availability of gadgets and lack of knowledge regarding the utility of online software as barriers to online learning (Table 4).

\section{DISCUSSION}

The COVID-19 pandemic has had a tremendous effect on medical education. It is also challenging for medical educationists' ability to adapt to this
Table 3: Perceptions and attitudes of the students toward online teaching.

\begin{tabular}{|c|c|c|c|}
\hline \multirow[t]{2}{*}{ Characteristics } & \multicolumn{3}{|c|}{ Categories } \\
\hline & $\begin{array}{c}\text { Agreed } \\
\text { n (\%) }\end{array}$ & $\begin{array}{l}\text { Disagreed } \\
\mathrm{n}(\%)\end{array}$ & $\begin{array}{c}\text { Neutral } \\
\mathrm{n}(\%)\end{array}$ \\
\hline $\begin{array}{l}\text { Online education enables students to } \\
\text { continue their education similarly to } \\
\text { the traditional approach. }\end{array}$ & $\begin{array}{c}18 \\
(11.9)\end{array}$ & $\begin{array}{c}98 \\
(64.9)\end{array}$ & $\begin{array}{c}35 \\
(22.2)\end{array}$ \\
\hline $\begin{array}{l}\text { I am able to easily access the } \\
\text { Internet for my studies. }\end{array}$ & $\begin{array}{c}91 \\
(60.3)\end{array}$ & $\begin{array}{c}21 \\
(13.9)\end{array}$ & $\begin{array}{c}39 \\
(25.8)\end{array}$ \\
\hline $\begin{array}{l}\text { With the existence of online } \\
\text { education, the pandemic does not } \\
\text { disrupt my future plans. }\end{array}$ & $\begin{array}{c}14 \\
(9.3)\end{array}$ & $\begin{array}{c}96 \\
(63.6)\end{array}$ & $\begin{array}{c}41 \\
(27.2)\end{array}$ \\
\hline $\begin{array}{l}\text { I feel comfortable to actively } \\
\text { communicate with my classmates } \\
\text { and instructors online. }\end{array}$ & $\begin{array}{c}37 \\
(24.5)\end{array}$ & $\begin{array}{c}50 \\
(33.1)\end{array}$ & $\begin{array}{c}64 \\
(42.4)\end{array}$ \\
\hline $\begin{array}{l}\text { I have satisfactory computer skills } \\
\text { for dealing with online courses and } \\
\text { assignments. }\end{array}$ & $\begin{array}{c}96 \\
(63.6)\end{array}$ & $\begin{array}{c}21 \\
(13.9)\end{array}$ & $\begin{array}{c}34 \\
(22.2)\end{array}$ \\
\hline $\begin{array}{l}\text { Online learning saves time and effort } \\
\text { for both teachers and students. }\end{array}$ & $\begin{array}{c}58 \\
(38.4)\end{array}$ & $\begin{array}{c}58 \\
(38.4)\end{array}$ & $\begin{array}{c}35 \\
(23.2)\end{array}$ \\
\hline $\begin{array}{l}\text { It is essential that online learning } \\
\text { materials be of high quality for online } \\
\text { education. }\end{array}$ & $\begin{array}{c}100 \\
(66.2)\end{array}$ & $\begin{array}{c}18 \\
(11.9)\end{array}$ & $\begin{array}{c}33 \\
(21.9)\end{array}$ \\
\hline $\begin{array}{l}\text { Online learning will bring new } \\
\text { opportunities for organizing teaching } \\
\text { and learning. }\end{array}$ & $\begin{array}{c}94 \\
(62.3)\end{array}$ & $\begin{array}{c}17 \\
(11.3)\end{array}$ & $\begin{array}{c}40 \\
(26.5)\end{array}$ \\
\hline $\begin{array}{l}\text { Medical universities should adopt } \\
\text { online learning more extensively. }\end{array}$ & $\begin{array}{c}28 \\
(18.5)\end{array}$ & $\begin{array}{c}66 \\
(43.7)\end{array}$ & $\begin{array}{c}57 \\
(37.7)\end{array}$ \\
\hline $\begin{array}{l}\text { Online learning increases the quality } \\
\text { of learning as it integrates all forms } \\
\text { of media, that is, print, audio, video, } \\
\text { and animation. }\end{array}$ & $\begin{array}{c}53 \\
(35.1)\end{array}$ & $\begin{array}{c}42 \\
(27.8)\end{array}$ & $\begin{array}{c}56 \\
(37.1)\end{array}$ \\
\hline
\end{tabular}

Table 4: Challenges and barriers to online class.

\begin{tabular}{|c|c|c|c|}
\hline \multirow[t]{2}{*}{ Characteristics } & \multicolumn{3}{|c|}{ Categories } \\
\hline & $\begin{array}{l}\text { Agreed } \\
\text { n (\%) }\end{array}$ & $\begin{array}{c}\text { Disagreed } \\
\mathrm{n}(\%)\end{array}$ & $\begin{array}{c}\text { Neutral } \\
\mathrm{n}(\%)\end{array}$ \\
\hline $\begin{array}{l}\text { Online education makes me } \\
\text { uncomfortable because I don't have } \\
\text { the knowledge about the technology. }\end{array}$ & $\begin{array}{c}12 \\
(7.9)\end{array}$ & $\begin{array}{c}105 \\
(69.5)\end{array}$ & $\begin{array}{c}34 \\
(22.5)\end{array}$ \\
\hline $\begin{array}{l}\text { I don't have an adequate availability } \\
\text { of hardware and software for online } \\
\text { education. }\end{array}$ & $\begin{array}{c}23 \\
(15.2)\end{array}$ & $\begin{array}{c}94 \\
(62.3)\end{array}$ & $\begin{array}{c}34 \\
(22.5)\end{array}$ \\
\hline $\begin{array}{l}\text { Poor Internet as a barrier to online } \\
\text { education. }\end{array}$ & $\begin{array}{c}133 \\
(88.1)\end{array}$ & $\begin{array}{c}5 \\
(3.3)\end{array}$ & $\begin{array}{c}13 \\
(8.6)\end{array}$ \\
\hline $\begin{array}{l}\text { Frequent electricity cutoffs as a } \\
\text { barrier to online education. }\end{array}$ & $\begin{array}{c}90 \\
(59.6)\end{array}$ & $\begin{array}{c}29 \\
(19.2)\end{array}$ & $\begin{array}{c}32 \\
(21.2)\end{array}$ \\
\hline $\begin{array}{l}\text { Feeling a difficulty in maintaining } \\
\text { focus during online classes. }\end{array}$ & $\begin{array}{c}110 \\
(72.8)\end{array}$ & $\begin{array}{c}13 \\
(8.6)\end{array}$ & $\begin{array}{c}28 \\
(18.5)\end{array}$ \\
\hline $\begin{array}{l}\text { Spending more time on the Internet } \\
\text { causes stress and anxiety. }\end{array}$ & $\begin{array}{c}103 \\
(68.2)\end{array}$ & $\begin{array}{l}10 \\
(6.6)\end{array}$ & $\begin{array}{c}38 \\
(25.2)\end{array}$ \\
\hline $\begin{array}{l}\text { Unable to convince my parents to } \\
\text { online education. }\end{array}$ & $\begin{array}{c}7 \\
(4.6)\end{array}$ & $\begin{array}{c}115 \\
(76.2)\end{array}$ & $\begin{array}{c}29 \\
(19.2)\end{array}$ \\
\hline $\begin{array}{l}\text { Unable to maintain privacy for my } \\
\text { online classes. }\end{array}$ & $\begin{array}{c}29 \\
(19.2)\end{array}$ & $\begin{array}{c}64 \\
(42.4)\end{array}$ & $\begin{array}{c}58 \\
(38.4)\end{array}$ \\
\hline
\end{tabular}

unique situation [13]. The situation has forced medical educationists to think 'out of the box' and act innovatively with digital technologies [4].

Thus, this study was done to assess the feasibility of online learning: the impact of COVID-19 on 
undergraduate dermatology education. The results revealed that a majority of the students had positive attitudes toward online learning despite various challenges and barriers. The pandemic has affected all areas of life, including education. Educational institutions were shut down, both for the safety of the students and the communities. Social distancing measures have impeded students in assembling in learning labs, lecture halls, and small-group rooms [4]. In a similar way, our study revealed that, due to the COVID-19 pandemic, students were forced to return to their homes, due to which they were unable to continue their clinical learning in wards, which had led to an increase in mental stress and anxiety among medical students, making them more concerned about their future.

According to our study, Zoom and Dudal were the most commonly used tools for online learning. Also, the students preferred the Zoom application for their future studies. These results correspond to those obtained by Atreya et al. and Sandhu et al. [6,7].

\section{Perception/Attitudes toward Online Learning}

According to our study, the students had a positive attitude toward online learning. $38.4 \%$ of the students revealed a positive response toward the statement "online learning saves time and effort for both teachers and students," which corresponds with the findings by Panda et al. A significant percentage of the students $(66.2 \%)$ agreed with the statement "it is essential that online learning material be of high quality for online education," which corresponds with the findings by Panda et al. [14]. Likewise, 35.1\% of the students revealed a positive response toward the statement "online learning increases the quality of learning as it integrates all forms of media, that is, print, audio, video, and animation," which corresponds to the study by Panda et al. [14].

Similarly, a majority of the students $(63.6 \%)$ in our study agreed with the statement "I have satisfactory computer skills for dealing with online courses/ assignments." This was not consistent with a study by Muflih et al. In a similar way, a majority $(60.3 \%)$ of the students agreed with the statement "I am able to easily access the Internet for my studies," which is opposite to the findings by Muflih et al. [12].

Based on our study, the significant challenges and barriers to online education were lack of past experience in using online tools for learning, communication barriers such as a poor Internet connection, frequent electricity cutoffs, and difficulty in maintaining focus during online classes and stress and anxiety in using the Internet.

According to Muflih et al., the barriers to online education according to students were "lack of past experience in using online tools" (74.3\%), which is consistent with our study [12]. According to the findings of our study, the students agreed that, in resource-poor countries such as Nepal, a poor network (86.8\%), a poor Internet connection $(88.1 \%)$, and frequent electricity cutoffs $(59.6 \%)$ were the communication barriers for online learning, which is in accordance with Atreya et al. and Panda et al. $[7,14]$. Regarding the statement "spending more time on the Internet causes stress/ anxiety," a majority of the students (68.2\%) agreed, which is consistent with a study carried out by Rajab et al. and Kapasia et al. [15,16].

The study was limited by a small sample size. Similarly, the study was conducted in a single institution and hence may not be representative of the scenario throughout the country.

\section{CONCLUSION}

The study was conducted to determine the feasibility of online learning due to the emergence of COVID-19 among medical undergraduate students representing dermatology education. According to our study, online learning is feasible in resource-poor countries such as Nepal, yet various factors impose challenges on its success. Although the COVID-19 pandemic has culminated in the lockdown of medical universities, it provided opportunities for bringing innovations into effect. Such studies are missing in developing countries such as Nepal, thus further research is needed to explore these possibilities nationwide.

\section{Statement of Human and Animal Rights}

All the procedures followed were in accordance with the ethical standards of the responsible committee on human experimentation (institutional and national) and with the 2008 revision of the Declaration of Helsinki of 1975.

\section{Statement of Informed Consent}

Informed consent for participation in the study was obtained from all patients. 


\section{Ethical approval}

Undergraduate Medical Research Protocol Review Board (UMRPRB) of BPKIHS (code: 06/2020, date of approval: Sep. 15, 2020).

\section{REFERENCES}

1. Khalil R, Mansour AE, Fadda WA, Almisnid K, Aldamegh M, Al-Nafeesah A, et al. The sudden transition to synchronized online learning during the COVID-19 pandemic in Saudi Arabia: A qualitative study exploring medical students' perspectives. BMC Med Educ. 2020;20:285.

2. Huang R, Tlili A, Chang TW, Zhang X, Nascimbeni F, Burgos D. Disrupted classes, undisrupted learning during COVID-19 outbreak in China: Application of open educational practices and resources. Smart Learn Environ. 2020;7:19.

3. Hilburg R, Patel N, Ambruso S, Biewald MA, Farouk SS. Medical education during the coronavirus disease-2019 pandemic: Learning from a Distance. Adv Chronic Kidney Dis. 2020;27:412-7.

4. Piryani RM, Piryani S, Piryani S, Shankar PR, Shakya DR. Impact of COVID-19 Pandemic on Medical Education: Challenges and Opportunities for Medical educators in South Asia. J BP Koirala Inst Heal Sci. 2020;3:28-38.

5. Almaiah MA, Al-Khasawneh A, Althunibat A. Exploring the critical challenges and factors influencing the E-learning system usage during COVID-19 pandemic. Educ Inf Technol. 2020;25:5261-80.

6. Sandhu P, de Wolf M. The impact of COVID-19 on the undergraduate medical curriculum. Med Educ Online. 2020;25:20-2.

7. Atreya A, Acharya J. Distant virtual medical education during COVID-19: Half a loaf of bread. Clin Teach. 2020;17:418-9.

8. Mukhtar K, Javed K, Arooj M, Sethi A. Advantages, limitations and recommendations for online learning during covid-19 pandemic era. Pakistan J Med Sci. 2020;36:27-31.

9. Nic Dhonncha E, Murphy M. Learning new ways of teaching and assessment - The impact of Covid-19 on undergraduate dermatology education. Clin Exp Dermatol. 2021;46:170-1.

10. Silva CS, Souza MB, Filho RSS, de Medeiros LM, Criado PR. E-learning program for medical students in dermatology. Clinics. 2011;66:619-22.

11. Verma A, Verma S, Garg P, Godara R. Online teaching during COVID-19: Perception of medical undergraduate students. Indian J Surg. 2020;82:299-300.

12. Muflih S, Abuhammad S, Karasneh R, Al-Azzam S, Alzoubi K, Muflih M. Online Education for undergraduate health professional education during the COVID-19 pandemic: Attitudes, barriers, and ethical issues. Res Sq. 2020;1-17.

13. Tabatabai S. COVID-19 impact and virtual medical education. J Adv Med Educ Prof. 2020;8:140-3.

14. Panda S, Mishra S. E-Learning in a Mega Open University: Faculty attitude, barriers and motivators. EMI Educ Media Int. 2007;44:323-38.

15. Rajab M, Gazal A, Alkattan K. Challenges to online medical education during the COVID-19 pandemic. Cureus. 2020;12:e8966.

16. Kapasia N, Paul P, Roy A, Saha J, Zaveri A, Mallick R, et al. Impact of lockdown on learning status of undergraduate and postgraduate students during COVID-19 pandemic in West Bengal, India. Child Youth Serv Rev. 2020;116:105194.

Copyright by Sagar Pokhrel, et al. This is an open access article distributed under the terms of the Creative Commons Attribution License, which permits unrestricted use, distribution, and reproduction in any medium, provided the original author and source are credited.

Source of Support: Nil, Conflict of Interest: None declared. 